\title{
Prediction of Cardiorespiratory Fitness in Czech Adults: Normative Values and Association with Cardiometabolic Health
}

\author{
Geraldo A. Maranhao Neto 1,*(D), Iuliia Pavlovska 1,2 (D), Anna Polcrova 1,3 (D), Jeffrey I. Mechanick 4,5, \\ Maria M. Infante-Garcia ${ }^{1,6}$, Jose Pantaleón Hernandez ${ }^{7}$, Miguel A. Araujo ${ }^{8}$, Ramfis Nieto-Martinez ${ }^{6,9,10}$ \\ and Juan P. Gonzalez-Rivas ${ }^{1,6,9}$ (D)
}

check for updates

Citation: Maranhao Neto, G.A.; Pavlovska, I.; Polcrova, A.;

Mechanick, J.I.; Infante-Garcia, M.M.; Hernandez, J.P.; Araujo, M.A.; Nieto-Martinez, R.; Gonzalez-Rivas, J.P. Prediction of Cardiorespiratory Fitness in Czech Adults: Normative Values and Association with Cardiometabolic Health. Int. J. Environ. Res. Public Health 2021, 18 , 10251. https://doi.org/10.3390/ ijerph181910251

Academic Editor: Paul B. Tchounwou

Received: 20 August 2021

Accepted: 27 September 2021

Published: 29 September 2021

Publisher's Note: MDPI stays neutral with regard to jurisdictional claims in published maps and institutional affiliations.

Copyright: (C) 2021 by the authors. Licensee MDPI, Basel, Switzerland This article is an open access article distributed under the terms and conditions of the Creative Commons Attribution (CC BY) license (https:// creativecommons.org/licenses/by/ $4.0 /)$.
1 International Clinical Research Center (ICRC), St Anne's University Hospital (FNUSA), 65692 Brno, Czech Republic; iuliia.pavlovska@fnusa.cz (I.P.); anna.polcrova@fnusa.cz (A.P.); maria.garcia@fnusa.cz (M.M.I.-G.); juan.gonzalez@fnusa.cz (J.P.G.-R.)

2 Department of Public Health, Faculty of Medicine, Masaryk University, 65691 Brno, Czech Republic

3 Research Centre for Toxic Compounds in the Environment (RECETOX), Masaryk University, 65691 Brno, Czech Republic

4 The Marie-Josée and Henry R. Kravis Center for Cardiovascular Health at Mount Sinai Heart, Icahn School of Medicine at Mount Sinai, New York, NY 10029, USA; jeffreymechanick@gmail.com

5 Division of Endocrinology, Diabetes and Bone Disease, Icahn School of Medicine at Mount Sinai, New York, NY 10029, USA

6 Foundation for Clinic, Public Health, and Epidemiology Research of Venezuela (FISPEVEN INC), Caracas 1060, Venezuela; nieto.ramfis@gmail.com

7 EDU Medicine and Health, Digital Education Holdings Ltd., KKR 1320 Kalkara, Malta; j_pantaleon@hotmail.com

8 Department of Physical Education, School of Education, University of Los Andes, Mérida 5101, Venezuela; migmaar@hotmail.com

9 Department of Global Health and Population. Harvard TH Chan School of Public Health, Harvard University, Boston, MA 02115, USA

10 LifeDoc Health, Memphis, TN 38119, USA

* Correspondence: geraldo.neto@fnusa.cz; Tel.: +420-734-523-179

\begin{abstract}
Cardiorespiratory fitness (CRF) is a strong independent predictor of morbidity and mortality. However, there is no recent information about the impact of CRF on cardiometabolic risk specifically in Central and Eastern Europe, which are characterized by different biological and social determinants of health. In this cross-sectional study normative CRF values were proposed and the association between CRF and cardiometabolic outcomes was evaluated in an adult Czechian population. In 2054 participants (54.6\% females), median age 48 (IQR 19 years), the CRF was predicted from a non-exercise equation. Multivariable-adjusted logistic regressions were carried out to determine the associations. Higher CRF quartiles were associated with lower prevalence of hypertension, type 2 diabetes (T2D) and dyslipidemia. Comparing subjects within the lowest CRF, we see that those within the highest CRF had decreased chances of hypertension (odds ratio $(\mathrm{OR})=0.36 ; 95 \% \mathrm{CI}$ : 0.22-0.60); T2D (OR = 0.16; 0.05-0.47), low HDL-c (OR = 0.32; 0.17-0.60), high low-density lipoprotein $(\mathrm{OR}=0.33 ; 0.21-0.53)$, high triglycerides $(\mathrm{OR}=0.13 ; 0.07-0.81)$, and high cholesterol $(\mathrm{OR}=0.44 ;$ 0.29-0.69). There was an inverse association between CRF and cardiometabolic outcomes, supporting the adoption of a non-exercise method to estimate CRF of the Czech population. Therefore, more accurate cardiometabolic studies can be performed incorporating the valuable CRF metric.
\end{abstract}

Keywords: cardiorespiratory fitness; cardiometabolic risk factors; population health; adult; middle aged

\section{Introduction}

Cardiovascular disease (CVD) is the leading cause of mortality in Europe, accounting for $45 \%$ of all deaths [1]. Higher age, male sex, hypertension, type 2 diabetes (T2D), dyslipidemia, obesity, low physical activity, and smoking are the traditional risk factors for CVD [2]. Over the last three decades, cardiorespiratory fitness (CRF) has emerged 
as a strong independent predictor of all-cause and disease-specific mortality [3]. CRF is considered to be a potentially stronger predictor of mortality than traditional risk factors [4]. CRF is an important marker of cardiovascular health and provides a measure of the body's ability to transport, absorb, and utilize oxygen to energy transfer to the muscles during physical activities [5]. Improvement in CRF is associated with a lower risk of all-cause [6] and CVD mortality [7]. This improvement favorably influences the health by reducing cardiometabolic risk characterized by dysglycemia, abnormal adiposity, hypertension, and dyslipidemia [8]; reducing adiposity, platelets adhesion, and aggregation; increasing skeletal muscle mass, insulin sensitivity, glucose disposal, and lipoprotein lipase function; and improving lipid profile [9].

Valid and representative reference values are critical for the interpretation of CRF, and when possible, data should be reported in the context of already published data from the same reference population [10]. However, there is limited information about the CRF in Central and Eastern European populations. Two studies are noteworthy: the Czechoslovakian study of 1071 subjects aged between 12 and 55 years [11], and the Lithuanian study of 168 adults, aged between 20 and 60 years [12]. The first study [11] used the data collected more than 40 years ago, which limited the current applicability of results, especially since concepts of health promotion and primordial/primary prevention only emerged in the former Czechoslovakia after 1990 [8]. In the second study [12], the sample was not population representative.

Western European countries have more representative and normative data [13-17], enabling subsequent studies on the associations among CRF, cardiometabolic risk factors, and clinical outcomes in adults [18-27]. However, there is no representative and normative data on CRF in Central and Eastern European populations, limiting relevant information on the health status of this population. The high costs of implementation and time spent on CRF testing may be a principal reason for this lack of information, especially in epidemiological studies [28]. A non-exercise prediction model is a feasible alternative to assess CRF without exercise testing. In this case, CRF is estimated instead through regression equations and based on easily available variables (e.g., body mass index (BMI), waist circumference (WC), resting heart rate (RHR), smoking profile, and physical activity (PA) level), showing good accuracy and predictive ability [29]. This alternative approach has been associated with health outcomes in a heterogeneous and population-representative sample [30].

The present paper aims to (a) propose normative CRF values of a sample of adults aged between 25 and 64 years old in Czechia, estimated through a non-exercise prediction model CRF; and (b) evaluate the association between estimated CRF and cardiometabolic outcomes.

\section{Materials and Methods}

\subsection{Study Design and Population}

The study design was described previously [31]. In brief, the Kardiovize study is a cross-sectional, random evaluation of adults between 25 and 64 years old of Brno, Czechia. Brno is the second-largest city in Czechia, with 373,327 residents. Eligibility criteria included permanent residence in the city and registration (required by the law) with any of the 5 state-run health insurance companies

\subsection{Sampling}

Survey sampling was performed in January 2013 with technical assistance from the largest (state-run) health insurance company using the registries of all health insurance companies. Registration with a health insurance company is mandatory in the Czech Republic. No a priori calculation of the sample size was performed. A random sample of 3300 persons stratified by age and gender was adjusted for a response rate of $64.4 \%$ (as projected from the Czech post-MONICA study). Health insurance companies mailed invitation letters with a description of the study, ensuring confidentiality. Similar to the post-MONICA study, Kardiovize targeted 1\% of the adult urban population between 25 and 64 years old. Because the sample size was not reached, a second random sampling was 
performed, following the same methodology, with 3077 mailed invitations. Based on the two samplings with a total of 6377 randomly selected invitees, the overall response rate was $33.9 \%$ [31]. No information on non-respondents was available. For this analysis, subjects with type 1 diabetes were excluded. A total of 2160 individuals signed informed consent to participate and were enrolled, which was large enough to ensure the representativeness of various sociodemographic strata in the sample.

\subsection{Data Collection}

The questionnaires included demographics (age, education, and marital status), socioeconomic status, cardiovascular risk behaviors (smoking status, nutrition, alcohol consumption, and physical activity), family and personal history, medications, hospitalizations, and mental health. Laboratory analyses were performed on 12-h fasting whole blood samples, using a Modular SWA P800 analyzer (Roche, Basel, Switzerland); total cholesterol, triglycerides, and glucose were analyzed by using the enzymatic colorimetric method (Roche Diagnostics GmbH, Mannheim, Germany); and high-density lipoprotein cholesterol (HDL-c) was analyzed with the homogeneous method for direct measurement without precipitation (Sekisui Medical, Hachimantai, Japan). Low-density lipoprotein cholesterol (LDL-c) level was calculated according to the Friedewald equation when triglyceride levels were below $4.5 \mathrm{mmol} / \mathrm{L}$; if it was higher, LDL-c was analyzed by using the homogeneous method for direct measurement (Sekisui Medical, Hachimantai, Japan). Blood pressure (BP) was measured with the patient alone, using an automated office measurement device (BpTRU, model BPM 200; Bp TRU Medical Devices Ltd., Coquitlam, BC, Canada).

\subsection{Variables Definition}

Physical activity was assessed by using the International Questionnaire of Physical Activity (IPAQ), long version. Subjects were categorized as "active" if they had participated in vigorous physical activity 3 or more days per week, at least 20 min per day; moderateintensity physical activity or walking 5 or more days, at least 30 min per day; or any combination of walking, moderate-intensity activities, or vigorous-intensity activities 5 or more days per week, achieving a minimum of at least 600 metabolic equivalent for task (MET)-min/week [32]. Subjects categorized as "insufficiently active" were those who did not perform in any of the activities above.

Marital status was categorized into living alone (including single, divorced, and widowed) or living in a couple (including married and other partnerships). Educational level was categorized as primary, secondary, and higher. Household income was expressed in Euros / month and categorized as low " $<1200$ ", middle "1200-1800", or high " $>1800$ ". Smoking status was classified as "non-smokers" or "current smokers" (smoking daily or less than daily during the past year). Participants were categorized into "non-drinkers" (including abstainers and those who did not drink in the previous 12 months) and "drinkers". Alcohol consumption was assessed by the reported alcohol intake of the last week, expressed in the number of standard drinks. One standard drink was assessed as a glass of wine, bottle of beer, or shot of spirits, each corresponding to approximately $10 \mathrm{~g}$ of ethanol.

\subsection{Cardiometabolic Outcomes}

Hypertension was defined as BP $\geq 140 / 90 \mathrm{mmHg}$, self-report of hypertension, or taking anti-hypertensive medications. Type 2 diabetes was defined as fasting blood glucose $\geq 7 \mathrm{mmol} / \mathrm{L}$, self-report of T2D, or taking antidiabetic medications. Low HDLcholesterol was defined as $<1 \mathrm{mmol} / \mathrm{L}$ in men or $<1.2 \mathrm{mmol} / \mathrm{L}$ in women; high LDLcholesterol was defined as LDL $\geq 3 \mathrm{mmol} / \mathrm{L}$ or on lipid-lowering drugs, such as fibrates, nicotinic acid, and statins; hypertriglyceridemia was defined as triglycerides $\geq 1.7 \mathrm{mmol} / \mathrm{L}$ or on lipid-lowering drugs; hypercholesterolemia as total cholesterol $\geq 5.0 \mathrm{mmol} / \mathrm{L}$ or on lipid-lowering drugs [33]. 


\subsection{Cardiorespiratory Fitness Estimation}

The CRF was predicted from the non-exercise equation of Jackson et al. [34], including age, body mass index (BMI), waist circumference (WC), and resting heart rate (RHR) as continuous variables; and physical activity (PA) level and smoking status as dichotomous variables. The CRF values are expressed in MET units. The prediction equations were as follow:

CRF $($ Men $): 21.2870+($ age $\times 0.1654)-($ age $2 \times 0.0023)-(B M I \times 0.2318)-($ WC $\times 0.0337)-(R H R \times 0.0390)+$ $($ PA level $\times 0.6351)-($ smoking status $\times 0.4263)$

$\mathrm{CRF}($ Women $)=14.7873+($ age $\times 0.1159)-($ age $2 \times 0.0017)-(\mathrm{BMI} \times 0.1534)-(\mathrm{WC} \times 0.0088)-(\mathrm{RHR} \times 0.0364)+$ $($ PA level $\times 0.5987)-($ smoking status $\times 0.2994)$

\subsection{Data Analysis}

All statistical analyses were performed by using the STATA software (version 14.0, StataCorp, College Station, TX, USA). The Kolmogorov-Smirnov test was used to assess the normal distribution of variables BMI, waist circumference, and resting heart rate. Continuous variables were reported as the median and interquartile range (IQR) and compared by using the Mann-Whitney U test. Categorical variables were reported as frequency and percentage and compared using the Chi-squared or Fisher test. The Chi-squared test was used to assess the differences between variables across the cardiometabolic outcomes status and CRF categories. The CRF in METs was categorized in quartiles. The quartiles were sexand age-specific. Crude and multivariable-adjusted logistic regressions were carried out to determine the association between CRF and the presence of cardiometabolic outcomes. Model 1 was unadjusted. Model 2 was adjusted by age, sex, BMI, educational level, smoking status, alcohol drinking, and diuretic and vasodilator use (in case of hypertension); antidiabetic medication use (in case of T2D), and lipid-lowering medication use (in case of dyslipidemia). Statistical significance was set at $p<0.05$.

\section{Results}

\subsection{Subjects' Characteristics}

In total, 2054 subjects were included (Figure 1); 45.4\% were men, with a median age of 48.0 (IQR 19.0) years (Table 1). Men had a higher BMI and WC, and a higher prevalence of hypertension, T2D, high LDL-c, high cholesterol, high triglycerides, alcohol use, high education, and income levels than women. Women had a higher heart rate than men. Both sexes reported a high prevalence of sufficient physical activity $(87.7 \%$ in men and $88.8 \%$ in women; $p=0.279)$ and similar prevalence of smoking $(25.2 \%$ in men and $22.0 \%$ in women; $p=0.231)$.

\subsection{Association of Cardiorespiratory Fitness and Cardiometabolic Risk Factors}

The cutoff values in METs classified by age and sex to define the quartiles used are presented in Table 2. All the analyses considered the first quartile (Q1) as the lowest cutoff for CRF. Higher quartiles of CRF were associated with a lower prevalence of hypertension, T2D, and dyslipidemias (Table 3). Using logistic regression analysis, in the raw Model 1, we show a significant progressive reduction in the prevalence of cardiometabolic risk factors by each quartile and each MET estimated, except with high LDL-c and high cholesterol, where the difference was only observed with the highest quartile (Table 3). The fully adjusted Model 2 showed an independent association of CRF with all the assessed risk factors. Comparing with subjects with the lowest CRF (worse condition), we see that those with the highest CRF had a decreased chance of having hypertension by $64 \%$ (odds ratio $(\mathrm{OR})=0.36 ; 95 \% \mathrm{CI} 0.22-0.60)$, T2D by $84 \%(\mathrm{OR}=0.16 ; 95 \% \mathrm{CI} 0.05-0.47)$, low HLD-c by $68 \%(\mathrm{OR}=0.32 ; 95 \%$ CI $0.17-0.60)$, high LDL-c by $67 \%$ (OR $=0.33 ; 95 \%$ CI $0.21-0.53)$, high triglycerides by $87 \%(\mathrm{OR}=0.13$; $95 \mathrm{CI} 0.07-0.81)$, and high cholesterol by $56 \%(\mathrm{OR}=0.44$; 95\% CI 0.29-0.69) (Table 3). 


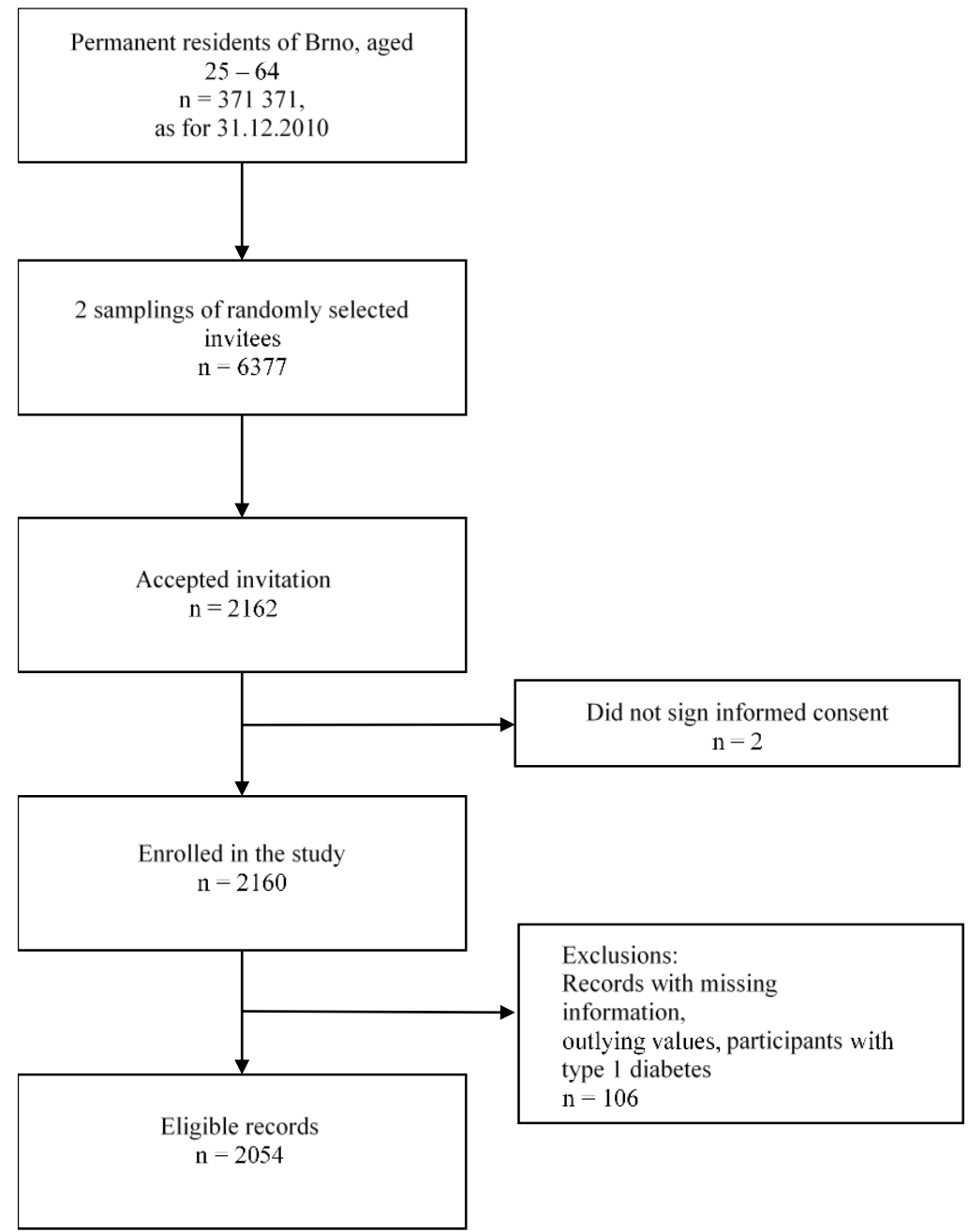

Figure 1. Flowchart of the recruitment, baseline data collection, and selection of the participants for the analysis.

Table 1. Characteristics of the subjects $(n=2054)$.

\begin{tabular}{cccc}
\hline Variables & $\begin{array}{c}\text { Men } \\
(\boldsymbol{n}=\mathbf{9 3 2})\end{array}$ & $\begin{array}{c}\text { Women } \\
(\boldsymbol{n}=\mathbf{1 1 2 2})\end{array}$ & $p$ \\
\hline & Age categories (\%) & & \\
\hline $25-34$ & 17.6 & 15.2 & \\
$35-44$ & 26 & 24.2 & 0.179 \\
\hline $55-54$ & 26.5 & 26.6 & $<0.001$ \\
55-64 & 29.9 & 36 & $<0.001$ \\
BMI (kg/m $\left.{ }^{2}\right)$ & $26.0(5.0)$ & $24.0(6.0)$ & $<0.001$ \\
Waist Circumference (cm) & $95.0(16.0)$ & $82.0(18.0)$ & $<0.001$ \\
Resting Heart Rate (bpm) & $68.6(14.0)$ & $71.4(12.2)$ & 0.158 \\
Hypertension (\%) & 43.7 & 33.4 & $<0.001$ \\
Type 2 Diabetes (\%) & 6.1 & 3.1 & $<0.001$ \\
Low HDL-c (\%) & 12.5 & 14.7 & 0.022 \\
High LDL-c (\%) & 69.4 & 57.1 & 0.279 \\
Hypertriglyceridemia (\%) & 29.5 & 13.5 & 0.231 \\
Hypercholesterolemia (\%) & 52.2 & 57.3 & $<0.001$ \\
Physically Active (\%) & 87.7 & 88.8 & 22 \\
Current Smokers (\%) & 25.2 & 78.8 & \\
\hline Alcohol Users (\%) & 90 & &
\end{tabular}


Table 1. Cont.

\begin{tabular}{|c|c|c|c|}
\hline Variables & $\begin{array}{c}\text { Men } \\
(n=932)\end{array}$ & $\begin{array}{l}\text { Women } \\
(n=1122)\end{array}$ & $p$ \\
\hline \multicolumn{4}{|c|}{ Educational Level (\%) } \\
\hline Low & 20.5 & 18.6 & \\
\hline Middle & 33.3 & 42.6 & \\
\hline High & 46.1 & 38.7 & $<0.001$ \\
\hline \multicolumn{4}{|c|}{ Household income (Euro) (\%) } \\
\hline Low $(<1200)$ & 33.5 & 50 & \\
\hline Middle (1200-1800) & 34 & 30.4 & \\
\hline High $(>1800)$ & 32.5 & 19.6 & $<0.001$ \\
\hline Living in Couple (\%) & 66.4 & 58.9 & $<0.001$ \\
\hline \multicolumn{4}{|c|}{ Medications (\%) } \\
\hline Diuretic & 7.6 & 6.1 & 0.21 \\
\hline Vasodilator & 24.4 & 19.7 & 0.011 \\
\hline Hypoglycemic agents & 3.5 & 4.5 & 0.294 \\
\hline Hypolipidemic agents & 11.8 & 9 & 0.056 \\
\hline
\end{tabular}

Table 2. Cardiorespiratory fitness classification (METs) according to quartiles of fitness ( $\mathrm{n}=2054)$.

\begin{tabular}{ccccc}
\hline Age Categories & Q1 (Lowest) & Q2 & Q3 & $\begin{array}{c}\text { Q4 } \\
\text { (Highest) }\end{array}$ \\
\hline \multicolumn{5}{c}{ Men $(\boldsymbol{n = 9 3 2 )}$} \\
\hline $25-34$ & $\leq 12.0$ & $>12.0-13.3$ & $>13.3-14.0$ & $>14.0$ \\
$35-44$ & $\leq 11.9$ & $>11.9-13.0$ & $>13.0-13.9$ & $>13.9$ \\
$45-54$ & $\leq 11.0$ & $>11.0-12.3$ & $>12.3-13.0$ & $>13.0$ \\
$55-64$ & $\leq 9.9$ & $>9.9-10.9$ & $>10.9-11.9$ & $>11.9$ \\
\hline \multicolumn{5}{c}{ Women $(\boldsymbol{n}=\mathbf{1 1 2 2})$} \\
\hline $5-34$ & $\leq 10.2$ & $>10.2-10.6$ & $>11.0$ \\
$35-44$ & $\leq 9.6$ & $>9.6-10.3$ & $>10.6-11.0$ & $>10.8$ \\
$55-54$ & $\leq 8.8$ & $>8.8-9.6$ & $>9.6-10.2$ & $>9.2$ \\
\hline 54 & $\leq 7.9$ & $>7.9-8.6$ & $>8.6-9.2$ & \\
\hline
\end{tabular}

Table 3. Association between CRF (in METs) and presence of cardiometabolic risk factors.

\begin{tabular}{|c|c|c|c|c|c|}
\hline \multicolumn{6}{|c|}{ CRF and Hypertension } \\
\hline \multirow{2}{*}{ Quartiles of Fitness } & Hypertension & Model 1 ${ }^{a}$ & \multirow{2}{*}{$95 \%$ CI } & Model $2^{b}$ & \multirow{2}{*}{$95 \%$ CI } \\
\hline & $(\%) * *$ & OR & & OR & \\
\hline Q1-lowest & 58.2 & 1 & & 1 & \\
\hline Q2 & 40.2 & $0.48^{* *}$ & $0.38-0.61$ & $0.69 *$ & $0.49-0.96$ \\
\hline Q3 & 28.7 & $0.29 * *$ & $0.22-0.37$ & $0.48^{* *}$ & $0.32-0.72$ \\
\hline Q4-highest & 21.1 & $0.19 * *$ & $0.14-0.25$ & $0.36^{* *}$ & $0.22-0.60$ \\
\hline METs per Unit & & $0.73 * *$ & $0.69-0.77$ & $0.59 * *$ & $0.50-0.70$ \\
\hline \multicolumn{6}{|c|}{ CRF and Type 2 Diabetes } \\
\hline \multirow{2}{*}{ Quartiles of Fitness } & Type 2 Diabetes & Model 1 a & \multirow{2}{*}{$95 \% \mathrm{CI}$} & Model $2^{c}$ & \multirow{2}{*}{$95 \% \mathrm{CI}$} \\
\hline & $(\%) * *$ & OR & & OR & \\
\hline Q1-lowest & 10.3 & 1 & & 1 & \\
\hline Q2 & 4 & $0.36^{* *}$ & $0.22-0.60$ & $0.48^{*}$ & $0.26-0.88$ \\
\hline Q3 & 1.6 & $0.15 * *$ & $0.07-0.31$ & $0.22 * *$ & $0.09-0.54$ \\
\hline Q4-highest & 1.1 & $0.10 * *$ & $0.04-0.24$ & $0.16^{* *}$ & $0.05-0.47$ \\
\hline METs per Unit & & $0.79 * *$ & $0.71-0.88$ & $0.50^{* *}$ & $0.36-0.70$ \\
\hline
\end{tabular}


Table 3. Cont.

\begin{tabular}{|c|c|c|c|c|c|}
\hline \multicolumn{6}{|c|}{ CRF and Low HDL-c } \\
\hline \multirow{2}{*}{ Quartiles of Fitness } & \multirow{2}{*}{ Low HDL-c (\%) ** } & Model 1 ${ }^{a}$ & \multirow{2}{*}{$95 \%$ CI } & Model 2d & \multirow{2}{*}{$95 \% \mathrm{CI}$} \\
\hline & & OR & & OR & \\
\hline Q1-lowest & 26.1 & 1 & & 1 & \\
\hline Q2 & 14.9 & $0.49 * *$ & $0.36-0.67$ & 0.86 & $0.59-1.24$ \\
\hline Q3 & 7.4 & $0.23 * *$ & $0.15-0.33$ & $0.47^{* *}$ & $0.29-0.77$ \\
\hline Q4-highest & 4.1 & $0.12 * *$ & $0.07-0.20$ & $0.32 * *$ & $0.17-0.60$ \\
\hline METs per Unit & & $0.71 * *$ & $0.66-0.76$ & 0.82 & $0.67-1.00$ \\
\hline \multicolumn{6}{|c|}{ CRF and High LDL-c } \\
\hline \multirow{2}{*}{ Quartiles of Fitness } & \multirow{2}{*}{ High LDL-c (\%) ** } & Model $1^{a}$ & \multirow{2}{*}{$95 \%$ CI } & Model $2^{d}$ & \multirow{2}{*}{$95 \%$ CI } \\
\hline & & OR & & OR & \\
\hline Q1-lowest & 66.8 & 1 & & 1 & \\
\hline $\mathrm{Q} 2$ & 65.4 & 0.94 & $0.73-1.20$ & 0.78 & $0.55-1.10$ \\
\hline Q3 & 61.2 & 0.78 & $0.61-1.00$ & $0.53^{* *}$ & $0.36-0.79$ \\
\hline Q4-highest & 56.1 & $0.63^{* *}$ & $0.49-0.82$ & $0.33 * *$ & $0.21-0.53$ \\
\hline METs per Unit & & $0.90 * *$ & $0.86-0.94$ & $0.82 *$ & $0.69-0.97$ \\
\hline \multicolumn{6}{|c|}{ CRF and Hypertriglyceridemia } \\
\hline \multirow{2}{*}{ Quartiles of Fitness } & \multirow{2}{*}{ Hypertriglyceridemia (\%) ** } & Model $1^{a}$ & \multirow{2}{*}{$95 \% \mathrm{CI}$} & Model $2^{d}$ & \multirow{2}{*}{$95 \% \mathrm{CI}$} \\
\hline & & OR & & OR & \\
\hline Q1-lowest & 35.7 & 1 & & 1 & \\
\hline Q2 & 23.9 & $0.57 * *$ & $0.44-0.74$ & $0.62 * *$ & $0.45-0.86$ \\
\hline Q3 & 14.2 & $0.30 * *$ & $0.22-0.40$ & $0.33^{* *}$ & $0.22-0.50$ \\
\hline Q4-highest & 5.9 & $0.11 * *$ & $0.07-0.17$ & $0.13^{* *}$ & $0.07-0.23$ \\
\hline METs per Unit & & $0.91 * *$ & $0.87-0.96$ & $0.68 * *$ & $0.57-0.81$ \\
\hline \multicolumn{6}{|c|}{ CRF and Hypercholesterolemia } \\
\hline \multirow{2}{*}{ Quartiles of Fitness } & \multirow{2}{*}{ Hypercholesterolemia (\%) * } & Model $1^{a}$ & \multirow{2}{*}{$95 \% \mathrm{CI}$} & Model $2^{d}$ & \multirow{2}{*}{$95 \% \mathrm{CI}$} \\
\hline & & OR & & OR & \\
\hline Q1-lowest & 56.8 & 1 & & 1 & \\
\hline Q2 & 58.5 & 1.07 & $0.85-1.36$ & 0.89 & $0.65-1.21$ \\
\hline Q3 & 54.2 & 0.9 & $0.71-1.15$ & $0.65 *$ & $0.45-0.62$ \\
\hline Q4-highest & 49.6 & $0.75 *$ & $0.58-0.96$ & $0.44^{* *}$ & $0.29-0.69$ \\
\hline METs per Unit & & $0.89^{* *}$ & $0.85-0.93$ & 0.92 & $0.79-1.06$ \\
\hline
\end{tabular}

CRF-cardiorespiratory fitness; T2D—-type 2 diabetes; ${ }^{a}$ unadjusted; ${ }^{b}$ adjusted by age categories, sex, body mass index, educational level, smoker, alcohol user, and diuretic and vasodilator use; ${ }^{\mathrm{c}}$ adjusted by age categories, sex, body mass index, educational level, smoker, alcohol user, and antidiabetic medication; ${ }^{\mathrm{d}}$ adjusted by age categories, sex, body mass index, educational level, smoker, alcohol user, and lipid-lowering medication; ${ }^{*} p<0.05,{ }^{* *} p<0.01$. Chi2 for trend across quartiles of fitness.

\section{Discussion}

This is the first study aimed to describe the distribution of predicted CRF levels among men and women aged 25-64 years, divided into decades in the Czech population that can be used as a reference for future clinical studies (Table 2). The classification in quartiles was associated with several cardiometabolic outcomes. The main findings can be summarized as follows: after adjustment by age categories, sex, BMI, educational level, smoking, alcohol use, and specific medications, the prevalence of hypertension, T2D, and hypertriglyceridemia were inversely associated with higher CRF quartile. In addition, low HDL-c, high LDL-c, and hypercholesterolemia were inversely associated with quartiles three and four (Table 3).

Results from other studies are easily converted to METs $\left(\mathrm{VO}_{2} \mathrm{~mL} \cdot \mathrm{kg}^{-1} \cdot \mathrm{min}^{-1}\right.$ / $\left.3.5 \mathrm{~mL} \cdot \mathrm{kg}^{-1} \cdot \mathrm{min}^{-1}\right)$, allowing for a comparison with the present findings. For instance, the mean results (METs) in the present study (men 30-39 years $=12.9,40-49$ years $=12.4$, 
and 50-59 years $=11.1$; women 30-39 years $=10.4,40-49$ years $=9.7$, and 50-59 years $=9.0$ ) are higher in each age classification than those established from the Czechoslovakian population in the 1970s: (men 30-39 years $=10.3,40-49$ years $=10.1$, and 50-59 years $=9.3$; women $30-39$ years $=8.4,40-49$ years $=7.9$, and $50-59$ years $=7.2$ ) [11]. As an illustration of how specific normative data can be useful, the values corresponding to the 25th, 50th, and 75th percentiles for a 45-year-old man in the present study were generally higher than values in German and United Kingdom registries, with values for a 45-year-old woman roughly the same for men $(11.0,12.3$, and 13.1) and women $(9.6,10.1$, and 10.5) in the present study; and compared with men (7.1, 10.8, and 13.7) and women (5.7, 8.6, and 11.7) in Germany, and men $(8.9,10.6$, and 12.6) and women $(5.7,8.6$, and 11.7) in the United Kingdom, respectively [17]. The comparison with other populations is important to highlight particularities of the studied sample, but also with the goal of including CRF as another risk factor under surveillance and creating CRF registry in different countries.

The relationship between CRF and cardiometabolic outcomes has different mechanisms. Aerobic activities are known to influence CRF levels and to prevent development of hypertension [35]. Blood pressure reduction with higher CRF levels appears to result from a decrease in total peripheral resistance, due to neurohumoral and structural vascular adaptations, decreased sympathetic tone, increased local vasodilatory responses, and favorable changes among endogenous vasoconstriction and vasodilation factors [36]. Better CRF allows performing aerobic exercises with greater intensity, duration, and frequency. This translates into higher caloric expenditure during and after exercise, decreasing the risk for abnormal adiposity [37]. In addition, a higher CRF is a cornerstone in the control and prevention of T2D, by improving insulin sensitivity and maintaining glycemic control $[30,38]$. Improvements in CRF have also been associated with better HDL functionality, including higher cholesterol efflux capacity. Antioxidative and anti-inflammatory HDL properties inhibit the oxidation of LDL. Moreover, HDL can take-up lipid peroxides, byproducts of lipid oxidation, and transport them to the liver for excretion $[39,40]$. Increased HDL antioxidative capacity has been related to decreased cholesterol and triglyceride content [41].

The present results are consistent with previous literature using non-exercise models. For instance, the prevalence of hypertension in a sample from United States population (20-86 years) significantly decreased from the highest to lowest CRF tertiles (from $42.5 \%$ to $24.3 \%$ in men and 45.5 to 20.6 in women) [42] and it was also observed in British adults (35-70 years) (CRF quartiles from $32.9 \%$ to $8.9 \%$ in men and $37.2 \%$ to $7.2 \%$ in women) by Stamatakis et al. [43]. The same study showed a prevalence of T2D significantly decreasing across the CRF quartiles (from $7.0 \%$ to $0.9 \%$ in men and $5.8 \%$ to $0.4 \%$ in women), which was also observed in Brazilian subjects (20-59 years) (22.9\% versus $0.9 \%$ in men and $12.2 \%$ versus $1.8 \%$ in women) [30]. The association between CRF and dyslipidemia is very well documented [44-46]. In fact, there are non-exercise models that include dyslipidemia as an independent variable [47]. In relation to the specific components of dyslipidemia (low HDL-c, high LDL-c, hypertriglyceridemia, and hypercholesterolemia), to the best of our knowledge, this is the first study showing associations between non-exercise CRF and each one of the components of dyslipidemia.

Epidemiological data recently suggested that having a better CRF significantly decreases the risk of hospitalization and dying from COVID-19 [48,49]. This decrease in risk can be mediated by an improvement in the cardiometabolic profile especially in individuals with obesity or overweight, insulin resistance, and diabetes [50]. Physical activity is a modifiable behavior that positively influences CRF level and can be a mitigation strategy against COVID-19 [49], especially in Czechia, where, in contrast to the decreasing burden and mortality related to CVD and certain cardiometabolic outcomes, the prevalence of dysglycemia and abnormal adiposity are increasing [8]. However, primary prevention programs in Czechia still require improvement. Concepts of health promotion and primary/primordial prevention only emerged in former Czechoslovakia after political change in 1990, and a system of public health control is still being established [8]. Therefore, the 
number of physically inactive adults has been increasing [51], and only recently have multi-morbidity care models [52] been applied [53,54]. A diligent focus on risk factors, including physical activity and fitness, is needed to slow down, stop, or even reverse cardiometabolic-based chronic disease progression $[8,53]$.

Among the main criticisms of non-exercise models are the inability to account for inter-individual variability [55]. However, the capacity to classify the CRF levels [56] and to associate them with cardiometabolic variables makes the method very useful for epidemiological studies. This study is the first to present the associations of a non-exercise model of CRF assessment with a broad range of cardiovascular outcomes. The present study also demonstrates generalizability of the model in a different and representative population. The city of Brno, a single urban setting, would represent the urban population of Czechia [57]. Limitations of the analysis are related to the cross-sectional design, which does not allow a causal relationship and the inclusion of self-reported behaviors, especially physical activity level, which might bias results.

\section{Conclusions}

Age- and sex-specific CRF normative values were estimated from a non-exercise model in a representative sample of 2054 Czech citizens from 25 to 64 years old. The generated CRF quartiles showed an inverse association with different cardiometabolic outcomes and support the adoption of the non-exercise method to obtain relevant information on the health status of the Czech population. With these results, more accurate cardiometabolic studies can be performed that incorporate the valuable CRF metric.

Author Contributions: Conceptualization, G.A.M.N. and J.P.G.-R.; methodology, G.A.M.N. and J.P.G.-R.; formal analysis, G.A.M.N.; writing-original draft preparation, G.A.M.N., J.P.G.-R., I.P., A.P., M.M.I.-G., J.P.H. and M.A.A.; writing-review and editing, J.P.G.-R., R.N.-M. and J.I.M. All authors have read and agreed to the published version of the manuscript.

Funding: The Kardiovize study was supported by the European Regional Development FundProject FNUSAICRC (no. CZ.1.05/1.1.00/02.0123), by project no. LQ1605 from the National Program of Sustainability II (MEYS CR), by project ICRC-ERA-Human Bridge (no. 316345) funded by the 7th Framework Program of the European Union, and partly by a grant by the Ministry of Health of the Czech Republic (NT13434-4/2012), Project ENOCH (No. CZ.02.1.01/0.0/0.0/16_019/0000868).

Institutional Review Board Statement: The study was conducted according to the guidelines of the Declaration of Helsinki, and approved by the ethics committee of St Anne's University Hospital, Brno, Czech Republic (Reference Number: 2G/2012).

Informed Consent Statement: Informed consent was obtained from all subjects involved in the study.

Data Availability Statement: The data presented in this study are available upon request from the corresponding author. The data are not publicly available.

Acknowledgments: The authors are grateful to all participants of the study.

Conflicts of Interest: Mechanick has received honoraria for lectures and program development from Abbott Nutrition International. Nieto-Martinez has received honoraria for lectures from Merck. The other authors have not conflict of interest.

\section{References}

1. Movsisyan, N.K.; Vinciguerra, M.; Medina-Inojosa, J.R.; Lopez-Jimenez, F. Cardiovascular Diseases in Central and Eastern Europe: A Call for More Surveillance and Evidence-Based Health Promotion. Ann. Glob. Health 2020, 86, 21. [CrossRef] [PubMed]

2. Cobb, F.R.; Kraus, W.E.; Root, M.; Allen, J.D. Assessing risk for coronary heart disease: Beyond Framingham. Am. Heart J. 2003, 146, 572-580. [CrossRef]

3. Kokkinos, P.; Myers, J. Physical Activity, Cardiorespiratory Fitness, and Health: A Historical Perspective. In Cardiorespiratory Fitness in Cardiometabolic Diseases; Kokkinos, P., Narayan, P., Eds.; Springer International Publishing: Cham, Switzerland, 2019; pp. 1-9.

4. Ross, R.; Blair, S.N.; Arena, R.; Church, T.S.; Despres, J.P.; Franklin, B.A.; Haskell, W.L.; Kaminsky, L.A.; Levine, B.D.; Lavie, C.J.; et al. Importance of Assessing Cardiorespiratory Fitness in Clinical Practice: A Case for Fitness as a Clinical Vital Sign: A Scientific Statement From the American Heart Association. Circulation 2016, 134, e653-e699. [CrossRef] [PubMed] 
5. $\quad$ Lamoureux, N.R.; Fitzgerald, J.S.; Norton, K.I.; Sabato, T.; Tremblay, M.S.; Tomkinson, G.R. Temporal Trends in the Cardiorespiratory Fitness of 2,525,827 Adults Between 1967 and 2016: A Systematic Review. Sports Med. 2019, 49, 41-55. [CrossRef] [PubMed]

6. $\quad$ Blair, S.N.; Kohl, H.W.; Paffenbarger, R.S.; Clark, D.G.; Cooper, K.H.; Gibbons, L.W. Changes in physical fitness and all-cause mortality. A prospective study of healthy and unhealthy men. JAMA 1995, 273, 1093-1098. [CrossRef] [PubMed]

7. Farrell, S.W.; DeFina, L.F.; Radford, N.B.; Leonard, D.; Barlow, C.E.; Pavlovic, A.; Willis, B.L.; Haskell, W.L.; Lee, I.M. Relevance of Fitness to Mortality Risk in Men Receiving Contemporary Medical Care. J. Am. Coll. Cardiol. 2020, 75, 1538-1547. [CrossRef] [PubMed]

8. Pavlovska, I.; Polcrova, A.; Mechanick, J.I.; Brož, J.; Infante-Garcia, M.M.; Nieto-Martínez, R.; Maranhao Neto, G.A.; Kunzova, S.; Skladana, M.; Novotny, J.S.; et al. Dysglycemia and Abnormal Adiposity Drivers of Cardiometabolic-Based Chronic Disease in the Czech Population: Biological, Behavioral, and Cultural/Social Determinants of Health. Nutrients 2021, 13, 2338. [CrossRef] [PubMed]

9. LaMonte, M.J. Physical Activity, Fitness, and Coronary Heart Disease. In Cardiorespiratory Fitness in Cardiometabolic Diseases; Kokkinos, P., Narayan, P., Eds.; Springer International Publishing: Cham, Switzerland, 2019; pp. 295-318.

10. Balady, G.J.; Arena, R.; Sietsema, K.; Myers, J.; Coke, L.; Fletcher, G.F.; Forman, D.; Franklin, B.; Guazzi, M.; Gulati, M.; et al. Clinician's Guide to cardiopulmonary exercise testing in adults: A scientific statement from the American Heart Association. Circulation 2010, 122, 191-225. [CrossRef] [PubMed]

11. Seliger, V.; Máček, M.; Horák, J.; Pirič, J.; Handzo, P.; Rouš, J.; Jirka, Z. Work capacity of the Czechoslovakian population. Eur. J. Appl. Physiol. Occup. Physiol. 1978, 39, 155-164. [CrossRef]

12. Grigaliūnienè, A.; Ramonas, A.; Čelutkienè, J.; Šileikienè, V.; Rudys, A.; Juocevičiu, A.; Laucevičiu, A. Cardiorespiratory parameters of exercise capacity in a healthy Lithuanian population: The pilot study. Hell. J. Cardiol. 2013, 54, $107-118$.

13. Tammelin, T.; Nayha, S.; Rintamaki, H. Cardiorespiratory fitness of males and females of northern Finland birth cohort of 1966 at age 31. Int. J. Sports Med. 2004, 25, 547-552. [CrossRef]

14. Koch, B.; Schäper, C.; Ittermann, T.; Spielhagen, T.; Dörr, M.; Völzke, H.; Opitz, C.F.; Ewert, R.; Gläser, S. Reference values for cardiopulmonary exercise testing in healthy volunteers: The SHIP study. Eur. Respir. J. 2009, 33, 389-397. [CrossRef]

15. Edvardsen, E.; Hansen, B.H.; Holme, I.M.; Dyrstad, S.M.; Anderssen, S.A. Reference values for cardiorespiratory response and fitness on the treadmill in a 20- to 85-year-old population. Chest 2013, 144, 241-248. [CrossRef]

16. Ekblom-Bak, E.; Ekblom, O.; Andersson, G.; Wallin, P.; Soderling, J.; Hemmingsson, E.; Ekblom, B. Decline in cardiorespiratory fitness in the Swedish working force between 1995 and 2017. Scand. J. Med. Sci. Sports 2019, 29, 232-239. [CrossRef]

17. Ingle, L.; Rigby, A.; Brodie, D.; Sandercock, G. Normative reference values for estimated cardiorespiratory fitness in apparently healthy British men and women. PLoS ONE 2020, 15, e0240099. [CrossRef]

18. Khan, H.; Jaffar, N.; Rauramaa, R.; Kurl, S.; Savonen, K.; Laukkanen, J.A. Cardiorespiratory fitness and nonfatalcardiovascular events: A population-based follow-up study. Am. Heart J. 2017, 184, 55-61. [CrossRef]

19. Appelqvist-Schmidlechner, K.; Vaara, J.P.; Vasankari, T.; Hakkinen, A.; Mantysaari, M.; Kyrolainen, H. Muscular and cardiorespiratory fitness are associated with health-related quality of life among young adult men. BMC Public Health 2020, $20,842$. [CrossRef]

20. Shigdel, R.; Dalen, H.; Sui, X.; Lavie, C.J.; Wisloff, U.; Ernstsen, L. Cardiorespiratory Fitness and the Risk of First Acute Myocardial Infarction: The HUNT Study. J. Am. Heart Assoc. 2019, 8, e010293. [CrossRef] [PubMed]

21. Garnvik, L.E.; Malmo, V.; Janszky, I.; Ellekjaer, H.; Wisloff, U.; Loennechen, J.P.; Nes, B.M. Physical activity, cardiorespiratory fitness, and cardiovascular outcomes in individuals with atrial fibrillation: The HUNT study. Eur Heart J. 2020, 41, $1467-1475$. [CrossRef] [PubMed]

22. Clausen, J.S.R.; Marott, J.L.; Holtermann, A.; Gyntelberg, F.; Jensen, M.T. Midlife Cardiorespiratory Fitness and the Long-Term Risk of Mortality: 46 Years of Follow-Up. J. Am. Coll. Cardiol. 2018, 72, 987-995. [CrossRef] [PubMed]

23. Aberg, N.D.; Adiels, M.; Lindgren, M.; Nyberg, J.; Georg Kuhn, H.; Robertson, J.; Schaufelberger, M.; Sattar, N.; Aberg, M.; Rosengren, A. Diverging trends for onset of acute myocardial infarction, heart failure, stroke and mortality in young males: Role of changes in obesity and fitness. J. Intern. Med. 2021. [CrossRef]

24. Eriksson, J.S.; Ekblom, B.; Andersson, G.; Wallin, P.; Ekblom-Bak, E. Scaling VO2max to body size differences to evaluate associations to CVD incidence and all-cause mortality risk. BMJ Open Sport Exerc. Med. 2021, 7, e000854. [CrossRef]

25. Holmlund, T.; Ekblom, B.; Borjesson, M.; Andersson, G.; Wallin, P.; Ekblom-Bak, E. Association between change in cardiorespiratory fitness and incident hypertension in Swedish adults. Eur. J. Prev. Cardiol. 2020, 2047487320942997. [CrossRef]

26. Laukkanen, J.A.; Kunutsor, S.K.; Yates, T.; Willeit, P.; Kujala, U.M.; Khan, H.; Zaccardi, F. Prognostic Relevance of Cardiorespiratory Fitness as Assessed by Submaximal Exercise Testing for All-Cause Mortality: A UK Biobank Prospective Study. Mayo Clin. Proc. 2020, 95, 867-878. [CrossRef] [PubMed]

27. Tarp, J.; Grontved, A.; Sanchez-Lastra, M.A.; Dalene, K.E.; Ding, D.; Ekelund, U. Fitness, Fatness, and Mortality in Men and Women From the UK Biobank: Prospective Cohort Study. J. Am. Heart Assoc. 2021, 10, e019605. [CrossRef] [PubMed]

28. Maranhao Neto, G.; Pedreiro, R.; Oliveira, A.; Machado, S.; Vieira, L.; Marques Neto, S.; Leon, A.P. Prediction of cardiorespiratory fitness in the brazilian population aged 20 to 59 years: A non-exercise model approach with self-reported variables. Rev. Da Educ. Física/Uem 2019, 30, e3068. [CrossRef] 
29. Wang, Y.; Chen, S.; Lavie, C.J.; Zhang, J.; Sui, X. An Overview of Non-exercise Estimated Cardiorespiratory Fitness: Estimation Equations, Cross-Validation and Application. J. Sci. Sport Exerc. 2019, 1, 38-53. [CrossRef]

30. Maranhao Neto, G.A.; Alves, I.; Lattari, E.; Oliveira, A.J.; Machado, S.; Neto, S.M.; Sui, X. Association between type 2 diabetes and non-exercise estimated cardiorespiratory fitness among adults: Evidences from a middle-income country. Public Health 2020, 189, 110-114. [CrossRef] [PubMed]

31. Movsisyan, N.K.; Vinciguerra, M.; Lopez-Jimenez, F.; Kunzova, S.; Homolka, M.; Jaresova, J.; Cifkova, R.; Sochor, O. Kardiovize Brno 2030, a prospective cardiovascular health study in Central Europe: Methods, baseline findings and future directions. Eur. J. Prev. Cardiol. 2018, 25, 54-64. [CrossRef] [PubMed]

32. World Health Organization. The Global Action Plan on Physical Activity 2018-2030: More Active People for a Healthier World; World Health Organization: Geneva, Switzerland, 2018.

33. Visseren, F.L.J.; Mach, F.; Smulders, Y.M.; Carballo, D.; Koskinas, K.C.; Back, M.; Benetos, A.; Biffi, A.; Boavida, J.M.; Capodanno, D.; et al. 2021 ESC Guidelines on cardiovascular disease prevention in clinical practice. Eur. Heart J. 2021, 42, 3227-3337. [CrossRef]

34. Jackson, A.S.; Sui, X.; O'Connor, D.P.; Church, T.S.; Lee, D.C.; Artero, E.G.; Blair, S.N. Longitudinal cardiorespiratory fitness algorithms for clinical settings. Am. J. Prev. Med. 2012, 43, 512-519. [CrossRef]

35. Bakker, E.A.; Sui, X.; Brellenthin, A.G.; Lee, D.C. Physical activity and fitness for the prevention of hypertension. Curr. Opin. Cardiol. 2018, 33, 394-401. [CrossRef]

36. Phillips, S.A.; Das, E.; Wang, J.; Pritchard, K.; Gutterman, D.D. Resistance and aerobic exercise protects against acute endothelial impairment induced by a single exposure to hypertension during exertion. J. Appl. Physiol. (1985) 2011, 110, 1013-1020. [CrossRef]

37. Carbone, S.; Del Buono, M.G.; Ozemek, C.; Lavie, C.J. Obesity, risk of diabetes and role of physical activity, exercise training and cardiorespiratory fitness. Prog. Cardiovasc. Dis. 2019, 62, 327-333. [CrossRef] [PubMed]

38. Nojima, H.; Yoneda, M.; Watanabe, H.; Yamane, K.; Kitahara, Y.; Sekikawa, K.; Yamamoto, H.; Yokoyama, A.; Hattori, N.; Kohno, N. Association between aerobic capacity and the improvement in glycemic control after the exercise training in type 2 diabetes. Diabetol. Metab. Syndr. 2017, 9, 63. [CrossRef] [PubMed]

39. Soran, H.; Schofield, J.D.; Durrington, P.N. Antioxidant properties of HDL. Front. Pharm. 2015, 6, 222. [CrossRef] [PubMed]

40. Ruiz-Ramie, J.J.; Barber, J.L.; Sarzynski, M.A. Effects of exercise on HDL functionality. Curr. Opin. Lipidol. 2019, 30, 16-23. [CrossRef]

41. Khan, A.A.; Mundra, P.A.; Straznicky, N.E.; Nestel, P.J.; Wong, G.; Tan, R.; Huynh, K.; Ng, T.W.; Mellett, N.A.; Weir, J.M.; et al. Weight Loss and Exercise Alter the High-Density Lipoprotein Lipidome and Improve High-Density Lipoprotein Functionality in Metabolic Syndrome. Arter. Thromb. Vasc. Biol. 2018, 38, 438-447. [CrossRef]

42. Zhang, Y.; Zhang, J.; Zhou, J.; Ernstsen, L.; Lavie, C.J.; Hooker, S.P.; Sui, X. Nonexercise Estimated Cardiorespiratory Fitness and Mortality Due to All Causes and Cardiovascular Disease: The NHANES III Study. Mayo Clin. Proc. Innov. Qual Outcomes 2017, 1, 16-25. [CrossRef] [PubMed]

43. Stamatakis, E.; Hamer, M.; O’Donovan, G.; Batty, G.D.; Kivimaki, M. A non-exercise testing method for estimating cardiorespiratory fitness: Associations with all-cause and cardiovascular mortality in a pooled analysis of eight population-based cohorts. Eur. Heart J. 2013, 34, 750-758. [CrossRef] [PubMed]

44. Ohta, T.; Nagashima, J.; Sasai, H.; Ishii, N. Relationship of Cardiorespiratory Fitness and Body Mass Index with the Incidence of Dyslipidemia among Japanese Women: A Cohort Study. Int. J. Environ. Res. Public Health 2019, 16, 4647. [CrossRef] [PubMed]

45. Hsu, C.S.; Chang, S.T.; Nfor, O.N.; Lee, K.J.; Lee, S.S.; Liaw, Y.P. Effects of Regular Aerobic Exercise and Resistance Training on High-Density Lipoprotein Cholesterol Levels in Taiwanese Adults. Int. J. Environ. Res. Public Health 2019, 16, 2003. [CrossRef]

46. Mann, S.; Beedie, C.; Jimenez, A. Differential effects of aerobic exercise, resistance training and combined exercise modalities on cholesterol and the lipid profile: Review, synthesis and recommendations. Sports Med. 2014, 44, 211-221. [CrossRef] [PubMed]

47. Cáceres, J.M.; Ulbrich, A.Z.; Panigas, T.F.; Benetti, M. Equações de predição da aptidão cardiorrespiratória de adultos sem teste de exercícios físicos. Rev. Bras. Cineantropometria E Desempenho Hum. 2012, 14, 287-295. [CrossRef]

48. Brawner, C.A.; Ehrman, J.K.; Bole, S.; Kerrigan, D.J.; Parikh, S.S.; Lewis, B.K.; Gindi, R.M.; Keteyian, C.; Abdul-Nour, K.; Keteyian, S.J. Inverse Relationship of Maximal Exercise Capacity to Hospitalization Secondary to Coronavirus Disease 2019. Mayo Clin. Proc. 2021, 96, 32-39. [CrossRef] [PubMed]

49. Christensen, R.A.G.; Arneja, J.; St Cyr, K.; Sturrock, S.L.; Brooks, J.D. The association of estimated cardiorespiratory fitness with COVID-19 incidence and mortality: A cohort study. PLoS ONE 2021, 16, e0250508. [CrossRef] [PubMed]

50. Zbinden-Foncea, H.; Francaux, M.; Deldicque, L.; Hawley, J.A. Does High Cardiorespiratory Fitness Confer Some Protection Against Proinflammatory Responses After Infection by SARS-CoV-2? Obes. (Silver Spring) 2020, 28, 1378-1381. [CrossRef] [PubMed]

51. Mayo, X.; Liguori, G.; Iglesias-Soler, E.; Copeland, R.J.; Clavel San Emeterio, I.; Lowe, A.; Del Villar, F.; Jimenez, A. The active living gender's gap challenge: 2013-2017 Eurobarometers physical inactivity data show constant higher prevalence in women with no progress towards global reduction goals. BMC Public Health 2019, 19, 1677. [CrossRef] [PubMed]

52. Mechanick, J.I.; Farkouh, M.E.; Newman, J.D.; Garvey, W.T. Cardiometabolic-Based Chronic Disease, Adiposity and Dysglycemia Drivers: JACC State-of-the-Art Review. J. Am. Coll. Cardiol. 2020, 75, 525-538. [CrossRef] 
53. Pavlovska, I.; Mechanick, J.I.; Maranhao Neto, G.A.; Infante-Garcia, M.M.; Nieto-Martinez, R.; Kunzova, S.; Polcrova, A.; Vysoky, R.; Medina-Inojosa, J.R.; Lopez-Jimenez, F.; et al. Arterial Stiffness and Cardiometabolic-Based Chronic Disease: The Kardiovize Study. Endocr Pr. 2021, 27, 571-578. [CrossRef]

54. Gonzalez-Rivas, J.P.; Mechanick, J.I.; Hernandez, J.P.; Infante-Garcia, M.M.; Pavlovska, I.; Medina-Inojosa, J.R.; Kunzova, S.; Nieto-Martinez, R.; Brož, J.; Busetto, L.; et al. Prevalence of adiposity-based chronic disease in middle-aged adults from Czech Republic: The Kardiovize study. Obes. Sci. Pract. 2021. [CrossRef]

55. Peterman, J.E.; Harber, M.P.; Imboden, M.T.; Whaley, M.H.; Fleenor, B.S.; Myers, J.; Arena, R.; Finch, W.H.; Kaminsky, L.A. Accuracy of Nonexercise Prediction Equations for Assessing Longitudinal Changes to Cardiorespiratory Fitness in Apparently Healthy Adults: BALL ST Cohort. J. Am. Heart Assoc. 2020, 9, e015117. [CrossRef] [PubMed]

56. Maranhão Neto, G.A.; de Leon, A.P.; Lira, V.A.; Farinatti, P.T. Assessment of Cardiorespiratory Fitness without Exercise in Elderly Men with Chronic Cardiovascular and Metabolic Diseases. J. Aging Res. 2012, 2012, 518045. [CrossRef] [PubMed]

57. Movsisyan, N.K.; Sochor, O.; Kralikova, E.; Cifkova, R.; Ross, H.; Lopez-Jimenez, F. Current and past smoking patterns in a Central European urban population: A cross-sectional study in a high-burden country. BMC Public Health 2016, 16, 571. [CrossRef] 